\title{
Delusional Parasitosis Associated with Pemoline
}

\author{
Till Krauseneck Michael Soyka \\ Psychiatrische Klinik und Poliklinik der Ludwig-Maximilians-Universität, München, Deutschland
}

In delusional parasitosis a patient believes that he is infested with parasites or other small living organisms even though there is no supporting medical evidence. The disorder has been known for well over 100 years and has been given many different names. It is quite rare, occurring in 20 out of 10,000 psychiatric admissions [1-3], but the majority of patients are seen by dermatologists and other medical specialists [4]. The delusions are usually encapsulated and sometimes associated with a depressive disorder or use of illicit drugs. Freinhar [5] described three categories of delusional parasitosis: primary psychotic, secondary functional and secondary organic. The secondary functional group includes patients with a toxic manifestation.

\section{Case Report}

Mr. B. is a 39-year-old cook. He has been taking drugs (alcohol, tranquilizers, cannabis, stimulants and opioids) since the age of 16. Several withdrawal treatments failed. For the last 10 years he has been on a methadone substitution program and has been living in relatively stable conditions with $180 \mathrm{mg}$ of methadone and concomitant mild abuse of diazepam and cannabis. About 4-5 days before admission he rapidly developed a feeling of being infected by parasites. The delusion was so strong that he wrecked his apartment and almost poisoned himself with anthelmintic drugs. Furthermore he did not visit the substitution unit to receive his methadone and could not sleep for the last 3 days before admission.

On admission he was agitated with labile affect and a prominent delusion of "being infected with parasites'. Orientation and all other mental state components were intact. Skin lesions (excoriations and small ulcerations) caused by scratching were found on his lower legs and forearms.

$\mathrm{He}$ was first treated with perazin for sedation and, after he had calmed down, the medication was changed to fluspirilene (intramuscular) once a week. This quickly led to a remission within a few days and the patient was allowed to leave the hospital on an hourly basis to clean his apartment. After he returned, he again reported delusions of parasites. Several days later he had again recovered completely. He stayed at home over-night and after his return again had the feeling of being infected by parasites, he presented 'captured animals' to prove he was infected (matchbox sign). Urine screening for illicit drugs was always negative for cocaine or methamphetamines. He then admitted a more or less regular intake of pemoline in the 2-3 weeks prior to admission and during the occasions he had left the hospital. When he stopped taking pemoline he completely remitted and was discharged free of delusional parasitosis.

\section{Discussion}

Delusional parasitosis is a rare condition that occurs under various circumstances. It is mostly seen as a primary diagnosis in middle-aged or elderly women. Intoxication of cocaine, amphetamines, alcohol, pervitin, bromide and the administration of various medications such as phenelzine, corticosteroids, captopril, bleomycin, clonidin, gold and HAES are known to provoke the symptoms [6].

To our knowledge this is the first case of delusional parasitosis associated with pemoline. This finding is not surprising since pemoline has a similar pharmacologic action to amphetamine and methylphenidate, though pemoline is structurally unrelated to amphetamines and seems to be a more specific dopamine-mimetic agent. Clinically it is used for treating attention deficit disorder and is known to cause delusional disorders [7]. Interestingly it seems that through the intake of pemoline the delusional symptoms are triggered and seen shortly thereafter. Diagnosis can be difficult because pemoline is not de-

\begin{tabular}{ll}
\hline KARGER & ( 2005 S. Karger AG, Basel \\
Fax +4161306 1234 & 0254-4962/05/0382-0103\$22.00/0 \\
$\begin{array}{l}\text { E-Mail karger@karger.ch } \\
\text { www.karger.com }\end{array}$ & $\begin{array}{l}\text { Accessible online at: } \\
\text { www.karger.com/psp }\end{array}$
\end{tabular}

Dr. med. Till Krauseneck

Psychiatrische Klinik und Poliklinik der LMU München

Nussbaumstrasse 7

DE-80336 München (Deutschland)

E-Mail Till.Krauseneck@med.uni-muenchen.de 
tected by commercially available urinary tests for illicit drugs.

Another important finding in our case is the good response to fluspirilene given intramuscularly as a depot medication, which has also been described elsewhere [8]. It remains unclear if withdrawal alone would have also lead to full remission, but in our case treatment became necessary due to the agitation of the patient. As many physicians find it difficult to treat patients adequately (especially outpatients), fluspirilene may represent the best available treatment.

\section{References}

1 Marneros A, Deister A, Rhode A: Delusional parasitosis. Psychopathology 1988;21:261274.

2 Trabert W: 100 years of delusional parasitosis. Meta-analysis of 1,223 case reports. Psychopathology 1995;28:238-246.

3 Slaughter JR, Zanol K, Rezvani H, Flax J: Psychogenic parasitosis. Psychosomatics 1998;39: 491-500.

4 Musalek M, Kutzer E: The frequency of shared delusions in delusions of infestation. Eur Arch Psychiatry Neurol Sci 1990;239:263-266.
5 Freinhar JP: Delusions of parasitosis. Psychosomatics 1984;25:47-49.

6 Freudenmann RW: Delusions of parasitosis: An up-to-date review (in German). Fortschr Neurol Psych 2002;70:531-541.

7 Polchert SE, Morse RM: Pemoline abuse. JAMA 1985;254:946-947.

8 Frithz A: Delusions of infestation: Treatment by depot injections of neuroleptics. Clin Exp Dermatol 1979;4:458-488. 